\title{
EXPLORATION AND PRACTICE OF BEIJING BELL AND DRUM TOWERS SAFETY DETECTION PROJECT
}

\author{
Zhang Xunhu ${ }^{1}$, Yang Yongxing ${ }^{2}$, Zhang Jixian ${ }^{1}$, Liu Jinhu ${ }^{1}$, Wan Mingying ${ }^{1}$ \\ ${ }^{1}$ National Quality Inspection and Testing Center for Surveying and Mapping Products, $28^{\text {th }}$ Lianhuachi West Road, Beijing 100830, \\ China-8893784@qq.com; zhangjx@casm.ac.cn; 94586053@qq.com; 1055033299@qq.com \\ ${ }^{2}$ CIGIS LIMITED, 177 Dongzhimen nei Street, Beijing, China- 422488127@qq.com
}

KEY WORDS: Ancient Architecture, Safety Detection, 3D Laser Scanning, Non-destructive Detection, Evaluation, Appropriate Repair Recommendations

\begin{abstract}
:
Ancient architecture is one of the important historical and cultural heritage content, after many years trials and hardships, there will be a variety of diseases. To better protect the ancient architecture, we need to carry out a detailed investigation to detect and assess its structural safety and stability. Exploration of ancient architecture safety detection, need for an integrated comprehensive and detailed surveying and mapping means drawing detection map, using non-destructive detection techniques to check. We based on threedimensional laser scanning, integrated utilization technology mapping, ground penetrating radar detection technology, stress wave scanning technology, visual quality and damage prospecting techniques to detect the safety situation in Beijing Bell and Drum Towers. We put forward reasonable suggestions for appropriate repair, on the basis of a variety modal analysis detected the structures, the status of Beijing Bell and Drum Towers safety were assessed. The detection process in this paper has better prospects for the future work that explores cultural heritage of ancient architecture repair detection and appropriate assessment.
\end{abstract}

\section{INTRODUCTION}

Beijing Bell and Drum Towers is one of Beijing's iconic buildings. It is the largest, highest of city bells and drums in the history. Its value is multi-faceted, multi-angle, has a high historical and cultural landmark in the field of ancient architecture. There have been a variety of diseases after hundreds later of years of wind and rain in Beijing Bell and Drum Towers. In order to better protect Beijing Bell and Drum Towers, we use the most mature testing technology and analysis methods to carry out the exploration and detection of Beijing Bell and Drum Towers. The accurate and reliable information of Beijing Bell and Drum Towers is obtained. The information obtained ensures that the suggestions for the repair of Beijing Bell and Drum Towers are comprehensive, detailed and accurate.

As far as possible, non-destructive technology should be used to obtain data and information for safety detection of ancient architecture. Only when necessary, on the premise that it is harmless to the integrity of the building form and the safety of the structure after scientific argumentation, the micro damage detection technology is adopted to obtain the data information at least. For this reason, the collection Beijing Bell and Drum Towers' Historical Preservation and Restoration basic data on the use of the most sophisticated current testing techniques and methods of analysis, carry out a comprehensive site survey as possible detection, in order to obtain the most accurate and reliable information on the status quo, to ensure proper repair recommendations comprehensive, detailed and accurate.

\section{DETECTION CONTENT ANALYSIS}

Ancient architecture safety detection involves data collection and analysis, comprehensive surveying for the status quo, material strength testing, inspection damage of the structure and appearance quality, structural stability assessments and conservation proposals for repair and so on.

\subsection{Data collection and analysis}

We have collected Beijing Bell and Drum Towers' related archival material, including aspects of architectural history, scientific research, value research, repair and reinforcement, testing, monitoring, evaluation and mapping, etc., and all data collected systematically collate and analysis to support a comprehensive inspection of the main building. Data collection and analysis is an important work of heritage protection and the study of ancient architecture, for the full structure and usage of Beijing Bell and Drum Towers is great significance.

\subsection{Comprehensive surveying and mapping}

The comprehensive surveying and mapping results are the basic data and important basis of safety detection. Therefore, it is necessary to carry out topographic mapping and layout plan mapping of the protected area, fine mapping of the main building, drawing the plan and vertical section of the main building, collecting and processing high-definition images of the main building, levelling of each floor of the building, inclined wall surveying, wall roughness surveying, structural deformation measurements of main building.

\subsection{Detection material strength}

The main materials used in Beijing Bell and Drum Towers are brick and wood. In order to provide quantitative support for the deterioration of structural materials and structural performance evaluation and provide reliable basis for maintenance and reinforcement, objective quantitative analysis should be made for the strength of masonry bricks and mortar. 


\subsection{Structure Appearance Quality inspection and exploration Injury}

Ancient architecture structure and appearance quality inspection including artificial investigation, radar, threedimensional laser scanning, non-metallic ultrasonic analyser detects a combination of stone and brick masonry crack member, flash drums, flash crooked, seepage, crisp base member weathering and other diseases investigation, detection and mapping of wood structure materials cracking, crack, check internal aspects of defects torsional displacement, buckling and other defects, disease and create detailed map.

\subsection{Structure Stability Evaluation}

Diseases are classified on the basis of artificial investigation. Based on the three-dimensional laser scanning results, a detailed drawing of each disease where the building facade and all kinds of diseases were analysed to assess the impact of disease on the overall structure of the building safe and stable performance. Geological Exploration stability assessment including visual inspection and the base survey, basic foundations, structural settlement status and make a comprehensive analysis of the carrier; injury and damage to both the newly generated restoration investigation and analysis, determines the degree of damage to the quality appearance of the structure and the overall impact of the structural members of the force, on the overall stiffness of the various parts of the structure and specific analysis and evaluation of the law of force by the overall structure modelling entity; the comprehensive analysis of each content, scientific assessments on the structure and properties of Beijing Bell and Drum Towers. Study and establish the stability evaluation method of detection and investigation main building structure.

\subsection{Conservation recommendations}

The repair and reinforcement suggestions were put forward, according to the stability evaluation of Beijing Bell and Drum Towers foundation and the stability evaluation of the main building. The surface durability protection repair shall be carried out according to the surface deterioration and disease degree of materials, and the structural safety and stability repair shall be carried out according to the stress damage and deformation of components or structures.

\section{DETECTION EMBODIMENT}

In safety detection, we follow fundamental, research, nondestructive and advice on principle.

\subsection{Workflow}

The detecting operation flow chart is shown in Figure 1.

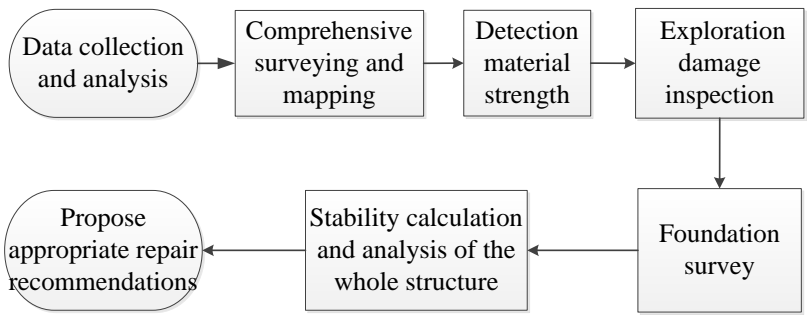

Figure 1. Detecting operation flowchart

\subsection{Comprehensive surveying and mapping}

Comprehensive surveying and mapping mainly develop in the following two aspects.

3.2.1 Three-dimensional scanning: We use a threedimensional laser scanning-based, supplemented by the traditional method of surveying and mapping, to carry out building space and structure mapping structure size (DANG X.B., 2011), comprehensive, accurate acquisition of heritage buildings all appearance, form data and maps, provide the basis data and three-dimensional model structure of Beijing Bell and Drum Towers for other professional work..

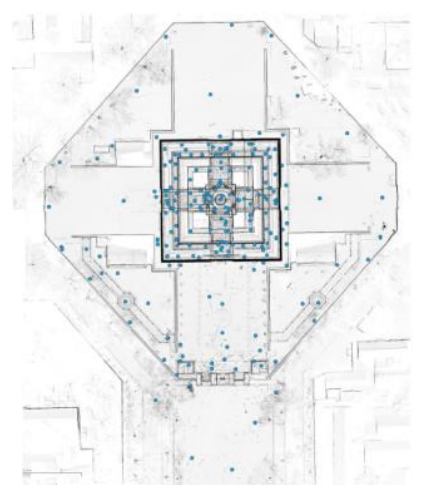

Figure 2. Three-dimensional scanning site

3.2.1.1 Mapping of the protected area: We combined GNSS and traverse surveying for Plane control network; Elevation control network is completed by grade IV Levelling Surveying. We using GPS RTK or total station automatically recorded observation data and computer-aided method in the terrain mapping.

3.2.1.2 Three-dimensional laser scanning mapping of the main building: We use Faro x330 3D laser scanner to obtain scanning data according to the first-class ground 3D laser scanning index (HE Xh., 2004). With more than 20 balls as the mosaic target feature, with the total station operations, to ensure data accuracy.

At last, all the components of Beijing Bell and Drum Towers are scanned and mapped. After obtaining the three-dimensional color point cloud, we made the color point cloud Orthophoto Image and point cloud splicing model, in which the color point cloud Orthophoto Image is the basic data for drawing the construction digital line drawing (YU M., Ding CH., Guo J.J., 2004).

3.2.1.3 The main building flat, vertical, sectional drawing: We used the cloud point as the base map In drawing the flat, vertical, cross-sectional rear view of each part. After on-site inspection and verification, the final result is achieved.

3.2.1.4 Building roofing high-resolution image acquisition and processing: We use Canon 5DsR SLR camera acquisition image. In the later stage, Photoshop is used to adjust and process the color separation temperature, color balance, image sharpness, etc. 
3.2.2 Three-dimensional laser point cloud data integration application: Based on the combination of total station survey, levelling survey and 3D laser scanning data, the survey of foundation settlement, wall cracking, skew flash and local component deformation was carried out.

Lay the attached levelling line and measure the relative height difference of each part by means of round-trip observation.

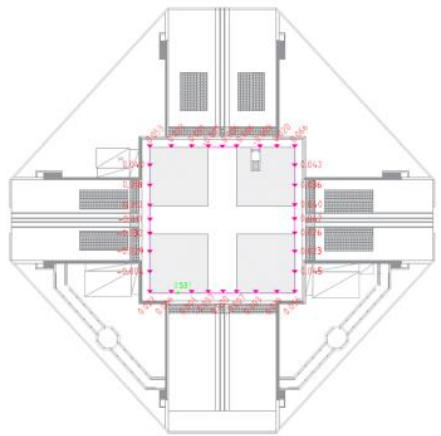

Figure 3. Clock Tower Base Platform level measurements

3.2.2.1 Tilt measurement wall: We use three-dimensional laser point cloud data to draw walls tilt measurement map. Draw walls cross-line vertical line, a fitting wall section break. Tilt the angle of the top and measure the yawing amount.

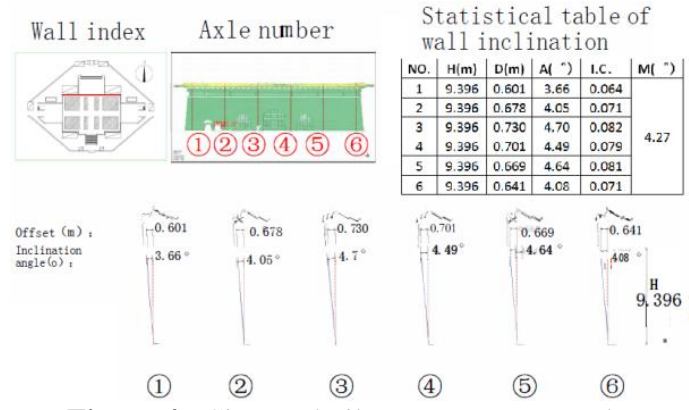

Figure 4. City Desk tilt measurement results

3.2.2.2 Wall roughness measurement: Cutting the threedimensional laser point cloud along the boundary of the wall, then using Geomagic as the fitting software in the measurement reference plane of the wall roughness measurement, finally formed the wall roughness result map

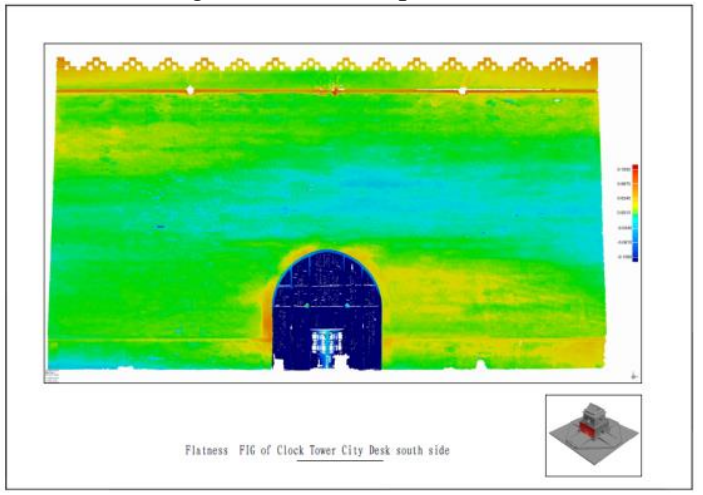

Figure 5. Clock tower wall roughness result map

\subsection{Detection material strength}

The strength inspection of the wall brick and mortar masonry.
3.3.1 Brick intensity detection: Structure dividing unit employed, the sample values of the real rebound hammer-zone, the intensity levels will be assessed based on the strength of the brick presumption.

After detection, the brick masonry compressive strength average of $4.54 \mathrm{MPa}$, the variation coefficient was 0.143 , the value of compressive strength $3.37 \mathrm{MPa}$, masonry brick compressive strength level less than MU7.5.

3.3.2 Mortar strength detection: Performed with SYJ-800B Mortar penetrometer sample batches of mortar strength test, and the inspection lot is estimated according to the intensity level of mortar presumption.

Mortar test results show, the mortar average strength of $2.0 \mathrm{Mpa}$, the minimum value of $1.6 \mathrm{MPa}$, masonry mortar strength estimation value is less than M2.0.

3.3.3 The relationship between test results and status quo preservation material: When we detect material strength, without destroying ancient architectural structure, select the amount of survey area using the means of rapid non-destructive detection, ancient architectural structures in masonry to make an objective quantitative analysis of the strength of brick and mortar. Binding site and the appearance quality inspection result exploration injury, and structural deterioration of performance evaluation for the material to provide quantitative support structure, and to provide a reliable basis for repair and reinforcement.

Test results shows that the strength of the wall can basically reflect the strength of the current structure material.

\subsection{Exploration damage inspection}

3.4.1 Masonry structural damage inspection: Comprehensively investigate and collect data on masonry diseases, confirm whether the brick is weathered, whether the mortar joint is full, whether the upper surface protective layer and protective paint fall off, whether the wooden door is damaged, and collect data on the disease severity.

3.4.2 Wood structure appearance quality inspection and survey damage: The material diseases and component diseases of wood members were detected. Material defects are mainly material cracks and internal defects, and component damage is mainly torsional displacement, buckling and imperfection. Using Vernier callipers and non-metal detection analyser (LIN J., TAN YF., LI SK., 2014b), the cracks on 23 sides of 20 wooden columns were detected. The results show that the crack width is about $1 \mathrm{~mm}-7 \mathrm{~mm}$, and the crack depth is about $22 \mathrm{~mm}-$ $143 \mathrm{~mm}$.

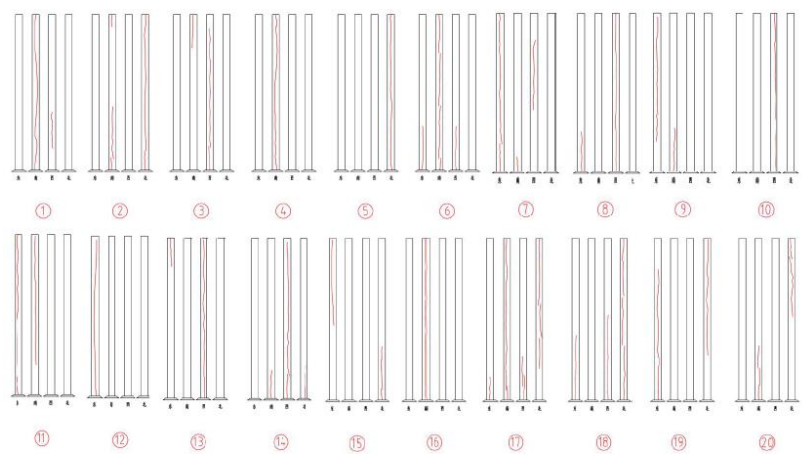

Figure 6. Four square pillar surface cracking 
We use the stress wave scanners and micro-drilling instrument resistance of the sample timber floor structural damage inside the column body defect detection (LI X., 2015b). Test items include whether there is corrosion inside the timber area, mechanical properties is intact. To obtain accurate scan results, we use the resistance meter of wood components for correcting defects in the single-path length of the defect, obtaining a more accurate defect area.

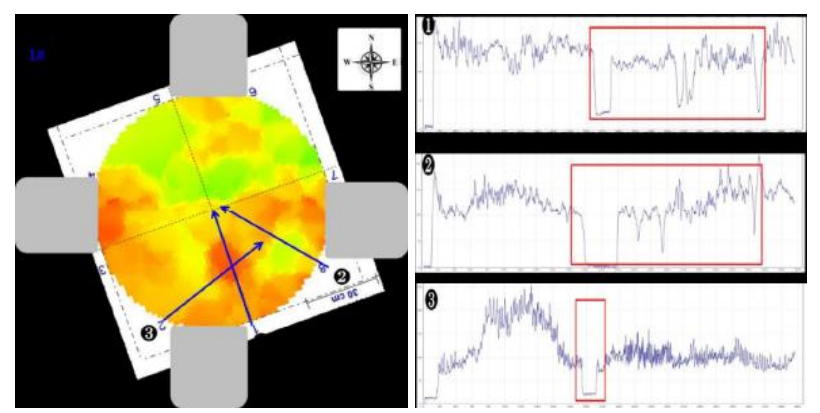

Figure 7. Cross-sectional scans and stress wave resistance cytometry results of No.1 wooden (height $136 \mathrm{~cm}$ )

Based on the test results, the mechanical strength of the circular column has been analysed (ZHANG F.L., 2013), and its bending strength has decreased by about $40 \%$, and the wood bearing capacity has also declined seriously. The strength safety of wood structure cannot be guaranteed if the load transmitted by the beam is borne by the timber column through the mortise structure alone. In the field, rectangular wing columns have been added in four directions of the southeast and northwest of the wooden columns, and multiple steel plates have been used to hoop them into a whole, so the overall strength of the columns has been enhanced.

3.4.3 Roof appearance quality inspection and survey damage: Because of the particularity of the building's location, it can't be photographed by UAV. We use lift car to collect high-definition image of building roof. After investigation, there were presence of cracks glazed tile, weathering off, plant diseases, and so on on roofing.

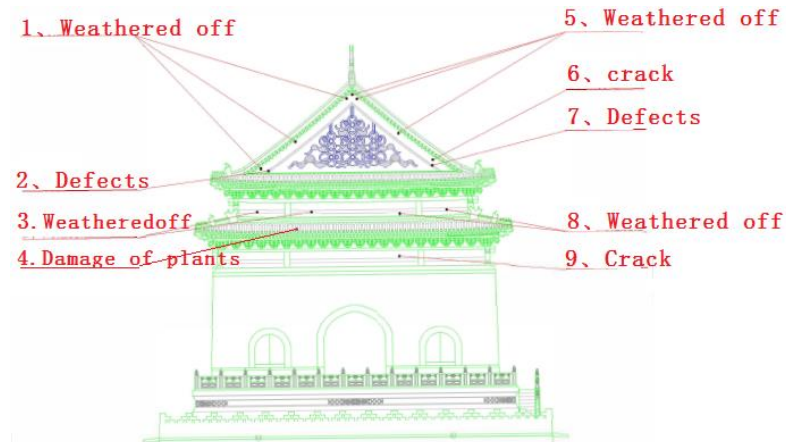

Figure 8. West facade roofing tile map disease of Beijing Bell Tower

\subsection{Foundation survey}

We use the foundation trenches, drilling, drilling situ testing (SPT, heavy dynamic penetration), drilling and sampling, crosshole seismic CT subsoil exploration, geological radar detection and other methods to carry out the foundation soil and city platform base survey.

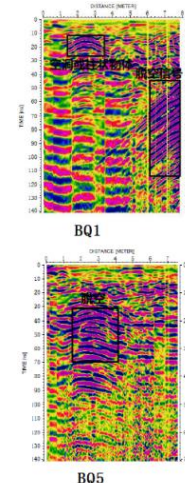

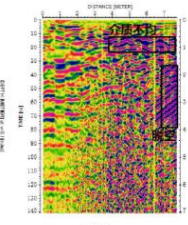

BQ2

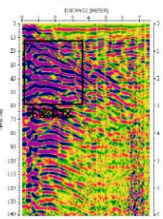

BQ6

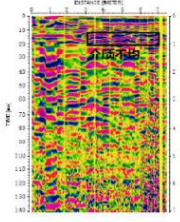

BQ3

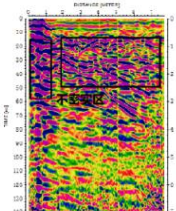

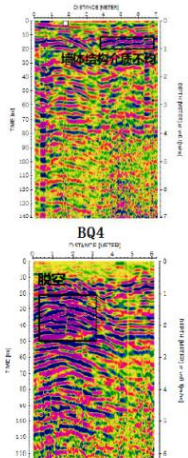

в08
Figure 9. Geological radar map of Beijing Drum Tower north wall

Table 1. Anomaly area of Beijing Drum Towers' north wall

\begin{tabular}{|c|c|c|c|}
\hline $\begin{array}{c}\text { Line } \\
\text { number }\end{array}$ & $\begin{array}{c}\text { scan line } \\
\text { ength }(\mathrm{m})\end{array}$ & $\begin{array}{c}\text { Depth } \\
(\mathrm{m})\end{array}$ & Feature of Anomaly reflects \\
\hline \multirow{2}{*}{ BQ1 } & 8 & $0.6-1.2$ & hollow or cylindrical body \\
\cline { 3 - 4 } & & $2.2-5.8$ & Void \\
\hline \multirow{2}{*}{ BQ2 } & 8 & $0.6-1.2$ & unevenness medium \\
\cline { 3 - 4 } & & $1.8-4.0$ & Void \\
\hline BQ3 & 8 & $0.6-1.0$ & unevenness medium \\
\hline BQ4 & 8 & $0.6-1.0$ & unevenness medium \\
\hline BQ5 & 7 & $1.4-3.4$ & Void \\
\hline BQ6 & 7 & $0.5-2.5$ & not dense area \\
\hline \multirow{2}{*}{ BQ7 } & 7 & $0.5-2.0$ & not dense area \\
\cline { 3 - 4 } & & $0.5-2.0$ & not dense area \\
\hline BQ8 & 6 & $1.0-2.4$ & Void \\
\hline
\end{tabular}

\subsection{Stability calculation and analysis of the whole structure}

Finite element numerical overall analysis of the main process is as follows:

3.6.1 Establishment of various 3D models: Based on the three-dimensional point cloud as the basic data (OU Y.H., 2015), carry out the surveying and mapping of horizontal and vertical building drawings, structural drawings, wall tilt of city platform, building tilt, wall flatness detection and city platform ground flatness detection.

3.6.2 Establish finite element model of the whole structure: We finite element model based on measurement geometry, test results and collected data (YANG M., 2016), the number of cells after the Boolean operation to obtain about 100,000, a three-dimensional tetrahedral solid co-order node processing unit. Midas Gen software is used for finite element analysis Beijing Bell and Drum Towers.

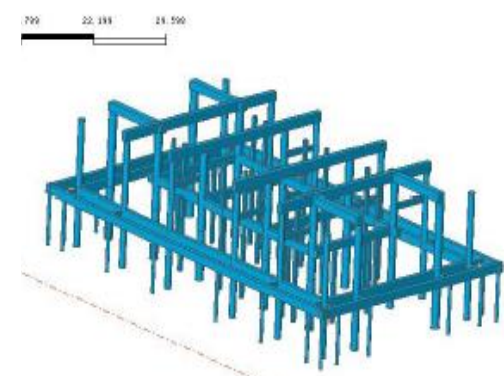

Figure 10. Load-Bearing Wooden structure model 


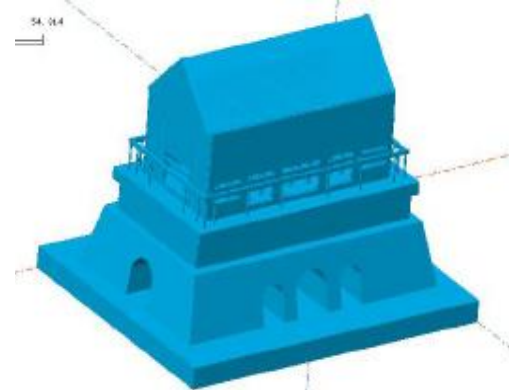

Figure 11. Overall geometric model

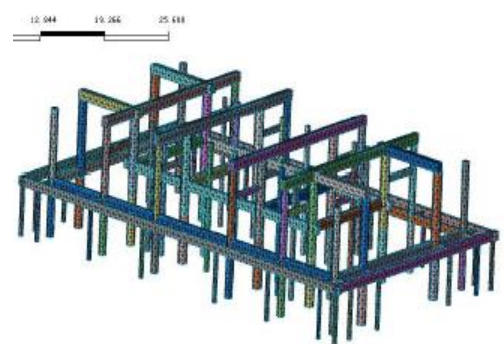

Figure 12. Load-bearing wood Construction framework grid

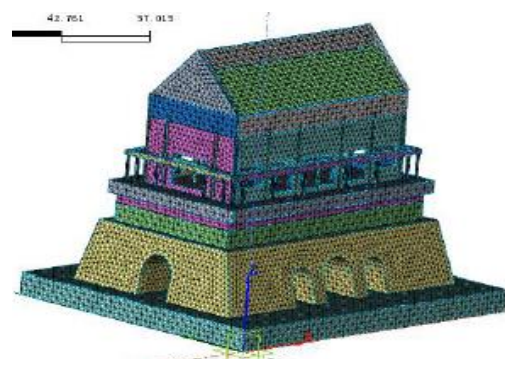

Figure 13. Overall model mesh

3.6.3 Calculation of load cases: When Condition Calculation analysis, assuming the base completely fixed on the ground, i.e., the bottom end of the fixed boundary conditions, $\mathrm{X}$, $\mathrm{Y}, \mathrm{Z}$-direction displacement and three $\mathrm{Rx}, \mathrm{Ry}, \mathrm{Rz}$ are zero angle in three directions. Linear elastic material properties is set to carry out its own weight load, vertical seismic loads, the horizontal seismic loads, wind load condition calculation.

Table 2. Structural analysis cases

\begin{tabular}{|l|r|r|c|}
\hline $\begin{array}{c}\text { Combination coefficient } \\
\text { Load type }\end{array}$ & $\begin{array}{c}\text { Permanent } \\
\text { load }\end{array}$ & $\begin{array}{c}\text { gravity } \\
\text { loads }\end{array}$ & $\begin{array}{c}\text { horizontal } \\
\text { seismic force }\end{array}$ \\
\hline Drum gravity loads & 1.2 & 1.2 & 1.2 \\
Roof Permanent load & 1.2 & 1.2 & 1.2 \\
Roof Variable load & 0 & 1.4 & $1.2 * 0.5$ \\
2nd floor Variable load & 0 & 1.4 & $1.2 * 0.5$ \\
2nd floor corridor load & 0 & 1.4 & $1.2 * 0.5$ \\
Seismic force & 0 & 0 & 1.3 \\
\hline
\end{tabular}

3.6.4 The results and analysis: We carried out a dynamic analysis, effective stress structure under seismic calculations, 1.2 Permanent loads +1.4 Variable loads.

3.6.4.1 Dynamic characteristics Modal analysis of the structure: Analysis permanent load mass conversion factor of 1.0 , the variable load was 0.5 mass conversion factor, calculated and extracted 3 front-order modes. The first mode and wooden structures are modified level $\mathrm{X}$ direction movable main vibration mode frequency $f=1.947$, corresponding to a period of $1.056 \mathrm{~s}$. The second vibration mode is a partial modification peripheral wall portion of the retaining timber main structural beams, a second order vibration mode frequency $f=1.107$, corresponding to a period of $0.903 \mathrm{~s}$. The third vibration mode and wooden structures are movable main flat direction $\mathrm{Y}$, three modes the frequency $f=1.109$, corresponding to a period of $0.901 \mathrm{~s}$.

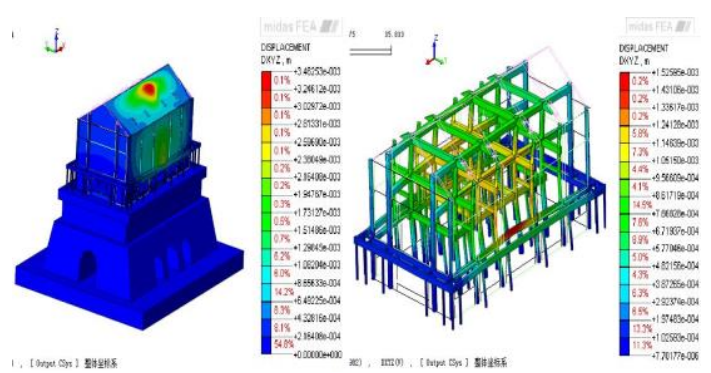

Figure 14. The 3rd-order vibration mode deformation

\subsubsection{Effective stress calculated structure Earthquakes:}

Deformation of the first vibration mode (oscillation mode) is the direction of an earthquake, the column bottom horizontal deformation moment larger, so a larger effective stress, effective stress is $1.37 \mathrm{MPa}$. The maximum stress in the masonry structure layer of the door opening, maximum effective stress is $0.39 \mathrm{MPa}$. Large deformation envelope (masonry) occurs out of the plane, is about $18 \mathrm{~m}$. Timbered frame larger deformation occurs along the direction of an earthquake, the deformation size is about $9 \mathrm{~mm}$. Timbered frame effective stress at the bottom of the column is large, the maximum shear stress of 0.39MPa.Shear stress at the bottom of the hole with a local stress concentration, the maximum shear stress is $0.21 \mathrm{MPa}$.

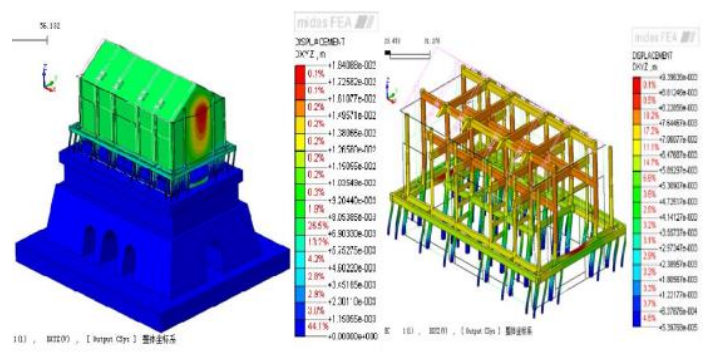

Figure 15. Structural deformation of earthquake

3.6.4.3 1.2 Permanent load + 1.4 Variable load: In permanent load and variable load of the interaction, due to the stress concentration weakening effect and a bottom, the bottom of the door opening is relatively large stress, approximately $0.47 \mathrm{MPa}$. To the upper timber frame construction, the overall frame column in compression, the compressive stress of the middle frame columns about 1.9Mpa. Drum bottom layer of the maximum deformation of about $11 \mathrm{~mm}$, the floor deformation is relatively large, a maximum of about $18 \mathrm{~mm}$, because the main floor to withstand live load floor and roof load applied load and wooden frames. Under load, deformation of the timber frame columns is uniform, the maximum deformation of about $13 \mathrm{~mm}$, a maximum deformation of the frame beams to $22 \mathrm{~mm}$. Wooden framework maximum effective stress on the bottom of the column, the maximum shear stress of $1.08 \mathrm{MPa}$. Shear stress at the bottom of the hole with a local stress concentration, the maximum shear stress of $0.26 \mathrm{MPa}$. 


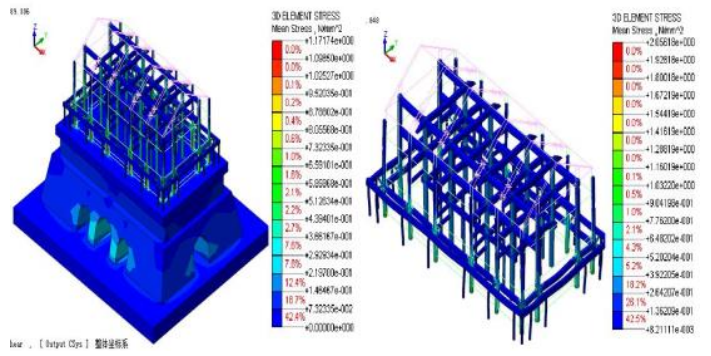

Figure 16. 1.2 Permanent load +1.4 Variable load overall maximum shear stress

3.6.4.4 Results of the analysis: Under the action of dead live load and seismic load, the effective stress meets the requirements of the code. The maximum shear stress appears at the corridor opening of the first floor of the drum tower, which exceeds the limit value of $0.06 \mathrm{mpa}$ of brick masonry material strength in the code. Because the direction of the maximum shear stress does not necessarily coincide with the direction of the mortar joint of the brick masonry, this conclusion only provides a reference for the analysis of the shear cracking of the brick masonry. The main load-bearing structure of the drum tower is the first floor brick masonry and the second floor wood frame. Under the action of constant live load and earthquake load, the stress distribution of the first layer of brick masonry is relatively uniform, local stress concentration appears in the first layer of door opening, and the maximum effective stress under the action of constant live load is $0.47 \mathrm{mpa}$. At the same time, the stiffness of the first layer masonry wall is large, and the seismic response is small under the seismic action. Under the action of the constant live load, the overall stress of the wood frame is relatively uniform, and the integrity of the main stressed wood frame in the middle is better. The maximum compressive stress occurs at the column base of $1.9 \mathrm{mpa}$. The side span frame is not completely connected with the middle frame, resulting in large plane deformation. Compared with the bottom masonry, the rigidity of wood frame is smaller, and the dynamic characteristics are all long period vibration mode, so the seismic response is smaller under the seismic action.

\section{COMPREHENSIVE ASSESSMENT AND RECOMMENDATIONS APPROPRIATE REPAIR}

\subsection{Ratings}

4.1.1 City platform masonry structural member ratings: City platform and safety assessment masonry building body divided into two stages. The first stage configured to assess and control the macroscopic identification based integrated assessment. The second stage to evaluate the bearing capacity checking the main structure and damage Binding comprehensive assessment. According to the second stage of evaluation criteria cannot be higher than the ratings of the first stage evaluation rating results. Considering the first stage and the second stage rating, masonry structures of City platform ranked two, main building masonry ranked two.

4.1.2 Wooden structure assessment: Based on "Ancient building structure safety appraisal technical specifications (Part 1: wood structure)" (DB11 / T 1190.1-2015), considering the wooden structural components and sub-ratings unit, the Drum Tower wooden structure rating $\mathrm{C}_{\mathrm{su}}$.

4.1.3 Evaluation of the roof structure: According to the appearance quality and damage inspection of the building roof, no appearance defects seriously affecting the structural safety are found on the building roof. However, there are some defects in appearance quality, such as weathering, fading, deglaze, cracks, whiteness of glaze surface, sundries and rain erosion. The roof structure is an enclosure structure, which is in normal use at present.

\subsection{Recommend appropriate repair}

\subsubsection{Platforms masonry structure Solution}

4.2.1.1 The recent focus on conservation projects: It is urgent to take reinforcement measures for the city platform structure; grout the mortar joints, repair the brick block surface, and reinforce the whole structure.

4.2.1.2 Long-term conservation projects: It is suggested that regular inspection should be carried out to ensure the safety and normal use of the structure.

\subsubsection{Masonry structure Solution}

4.2.2.1 The recent focus on conservation projects: It is urgent to take reinforcement measures for the building structure; grout the mortar joints, repair the brick block surface, and reinforce the whole structure.

4.2.2.2 Long-term conservation projects: It is suggested to repair, reinforce and repaint the four side facades, verandas column bodies and wooden doors. It is suggested that the structure of the City Platform should be inspected regularly to ensure the safety and normal use of the structure.

\subsubsection{Wooden structure Solution}

4.2.3.1 The recent focus on conservation projects: It is suggested that measures should be taken in time or immediately to ensure that the damage of components will not continue to develop and deteriorate, and ensure the safety of local structure. It is suggested that the timber columns with severe cracking, torsional displacement and buckling can also be strengthened by adding supports or hoops, and regular inspection should be carried out.

4.2.3.2 Long-term conservation projects: As soon as possible, carry wooden structure deformation monitoring, regular monitoring key parts of the wood components node. Conduct long-term monitoring of the overall structure, advance targeted repair and reinforcement. On the lower rack drum performances do isolation process, to prevent vibration impact on the structure of Drumming.

\subsubsection{Roof structure Solution}

4.2.4.1 The recent focus on conservation projects: On the roof weathering, cracking component repair or replacement of faded, deglaze component repair, cleaning the roof debris to prevent fall injuries.

4.2.4.2 Long-term conservation projects: Regular inspections of the roof structure, and do the appropriate maintenance conservation. 


\section{CONCLUSION}

In the safety detection project of Beijing Bell and Drum Towers, we use the relatively mature comprehensive surveying and mapping technology and detection means at present, and combine the 3D laser scanning technology, photogrammetry technology, geological radar detection technology, appearance quality and damage detection technology, stress wave scanning technology, etc. to comprehensively and effectively inspect the safety of Beijing Bell and Drum Towers. Through various structural modal analyses, the safety status of Beijing Bell and Drum Towers is evaluated, and reasonable suggestions for repair are put forward. The practice proves that the technical means and technological process applied in this project are reasonable and feasible, and the suggestions for the applicability are reasonable, which provides an effective idea for the future related work.

\section{REFERENCES}

DANG X.B., 2011. The Research and Application of 3D Laser Scanning Techniques in Building Deformation Monitoring. Chang'an University, Dissertation,22-27.

HE XH., 2004. Technical Standard for Inspection of Building Structure (GB/T 50344-2004), Ministry of Construction of the People's Republic of China, China Architecture \& Building Press, CHINA.

LI X., 2015. KEY TECHNOLOGY RESEARCH ON MATERIAL PERFORMANCE AND DAMAGE DETECTION FOR WOODEN COMPONENTS OF ANCIENT CHINESE BUILDING. Beijing Industry University, Dissertation, 102-121.

LIN J., TAN YF., LI SK., 2014. Guideline for Structural Safety Assessment of Modern Historic Building WW/T0048-2014, National Cultural Heritage Administration, Cultural Relics Publishing House, CHINA.

OU Y.H., 2015. Research on 3D Digital Modelling Method of Ancient Architecture in the Palace Museum, Journal of Beijing Union University, 29(03):10-14.

YANG M., 2016. STUDY THE SUITABILITY OF THE NONDESTRUCTIVE DETECTION METHODS OF ANCIENT WOOD INTERNAL DEFECTS. Beijing University, Dissertation, 55-67.

YU M., Ding CH., Guo J.J., 2004. The Study of ThreeDimensional Laser Scanning Technology For Ancient Architecture Surveying and Mapping. Science of Surveying and Mapping, 69-70+5-6.

ZHANG F.L., 2013. Research on Strengthening and Its Performance of Chinese Ancient Timber Structures. Xi'an University of Architecture and Technology, Dissertation, 65-72. 